\title{
Confronting AIDS: The Perspective of American Insurers
}

\author{
by John J. Creedon*
}

\section{Introduction}

\subsection{Scope of the epidemic}

When smallpox was eradicated in 1977 , many thought it was the last deadly viral epidemic to afflict mankind. Yet, as the last victims of smallpox were dying, another major epidemic was looming on the horizon. The first known cases of AIDS occurred in Africa in 1976. By 1979, the AIDS epidemic had broken out in the United States. Since then, the number of reported AIDS cases has climbed at an accelerating pace; the ravaging effects of this epidemic have been felt by many segments of our society.

The Centers for Disease Control (CDC) estimates that the Human Immunodeficiency Virus (HIV), the deadly virus that causes AIDS, has infected between 950,000 and 1.4 million Americans. Approximately 60,000 cases of AIDS and 35,000 AIDS deaths have been reported in the United States. Many other infected individuals have become ill and require medical care while not being officially classified as victims of AIDS. According to some estimates, the number of such individuals is well in excess of 100,000 .

\subsection{Costs of the epidemic}

The costs of treating the disease are substantial. Recent estimates indicate that the average cost of treating an AIDS victim in the United States is between $\$ 60,000$ and $\$ 75,000$.

The aggregate nationwide costs of the disease, while representing only a small fraction of the total costs of all illnesses, have been steadily rising. It is estimated that the personal medical care costs of AIDS victims in the United States rose from $\$ 630$ million in 1985 to $\$ 1.1$ billion in 1986 . The indirect costs attributable to loss of productivity from morbidity and premature mortality were estimated to have risen from $\$ 3.9$ billion in 1985 to $\$ 7.0$ billion in 1986.

\footnotetext{
* President and Chief Executive Officer Metropolitan Life Insurance Company New York, N. Y. Report presented at the 15 th General Assembly of the Geneva Association, The Hague, June 13-14, 1988.
} 
Because these figures include only the costs for those victims who met the CDC's definition of AIDS, total costs for all HIV infected individuals might well have been substantially higher. Those responsible for paying these costs have been finding them to be an increasing burden.

\subsection{Who pays for the epidemic?}

In the United States, most medical care costs are paid by the government, insurers, and businesses. The medical care costs of AIDS, which have been no exception, have exacerbated and called attention to certain problems currently faced by these payors.

In recent years, the cost of providing health care has risen more rapidly than other costs because the level of health care cost inflation has exceeded the general level of inflation and because the utilization of health care services has increased. Raising the funds necessary to pay for these increases has proved to be a difficult task. Government at all levels is under increasing pressure to hold the line on expenditures and taxes, while insurers and other businesses find these unanticipated costs chipping away at already thinning margins. The costs of the AIDS epidemic have further intensified the rapid increases in health care costs.

As the number of AIDS cases rises, the epidemic will impose an increasing burden on our health care structure. By 1991, the CDC projects that there will have been 270,000 AIDS cases with 180,000 resultant deaths in the United States. AIDS related medical care costs for 1991 alone are expected to be $\$ 8.5$ billion, representing $1.4 \%$ of the United States' personal health care expenditures, up from $0.3 \%$ in 1986.

\subsection{The role of insurers}

In the last few years, there has been a good deal of controversy in the United States regarding the role of insurers in funding the costs of AIDS. This paper will explore the industry's position that AIDS must be treated as any other disease. Then it will analyze the impact of AIDS on the industry.

While it is unlikely there will be a significant number of AIDS related insurance company insolvencies, most insurers will face large increases in claims levels in the coming years as a result of the AIDS epidemic. Insurers will need to develop strategies to manage the impact of the epidemic.

\section{The challenges posed by AIDS}

\subsection{Introduction}

The AIDS epidemic poses different challenges for group insurers and individual insurers because of variations in underwriting practices. An applicant for individual insurance will be issued a policy if he/she is deemed to be insurable based on the applicable underwriting standards (e.g., good health). With the exception of certain individually underwritten 
group coverages, an individual is generally covered under group insurance if he/she is a member of the insured group regardless of his/her own insurability. It is only necessary that the group as a whole meet the insurer's group underwriting standards.

\subsection{Group insurance}

To maintain an adequate spread of risks, group insurers provide coverage only to those groups not expected to have unusually poor experience and often do not cover pre-existing conditions for a limited period. To preclude possible antiselection, individual underwriting is frequently performed on those individuals in a group who decline coverage when first eligible and later decide to enroll. Despite these approaches, a large number of HIV infected individuals are covered under group insurance. The increasing AIDS caseload and the continued ability of HIV infected individuals to obtain coverage under group plans have served to increase the AIDS related liabilities of group insurers.

To deal with this increased exposure, group insurers are considering and, in some cases, implementing various strategies. These include adjustments to the rating and reserving structures and the institution of more limited benefits in certain situations. One possible adjustment to the rating structure would be to increase risk charges in anticipation of higher future costs. As these measures generally do not treat HIV infected individuals any differently than non-HIV infected individuals, they have not met with much resistance. However, in the case of individually underwritten supplemental coverages such as optional term life or dependent coverage, the same kinds of issues have been raised as for individual insurance.

\subsection{Individual insurance}

Insurers are obligated to pay all AIDS related claims on individuals who have a valid inforce policy. Because the screening of applicants for HIV infection has been in effect for only a few years and because individuals can become HIV infected after they buy their policies, many AIDS victims have valid inforce policies. Further, because of applicable state laws in the United States, policies inforce more than two years are considered valid regardless of any misrepresentations that might have been made by the insured at the time of issue, unless clearly fraudulent. Consequently, an individual who denied on the insurance application that he/she was HIV infected and who dies more than two years after issue will generally be covered under the terms of the policy.

Insurers believe that to be fair to other policyholders, they should be permitted to apply standard underwriting principles for AIDS when considering whether to issue a new policy. This would call for the exclusion from coverage of all individuals determined to be HIV infected. Because of the controversy this position has generated, it is necessary to analyze it in the context of American underwriting principles and government regulation. The extent of the underwriting that insurers will be permitted to apply will determine the scope and size of their AIDS related liabilities on new issues. 


\section{U.S. underwriting}

\subsection{Introduction}

Life and health insurance provide protection against the financial risks of death and illness by spreading these risks over a large group of individuals. Premiums are determined by calculating the expected costs for the group of insureds and then charging each individual his/her pro rata share of the cost. Each participant pays a relatively small amount so that those unfortunate few who incur substantial losses do not face financial devastation. This pooling of risks is a fundamental characteristic of insurance.

For the pooling mechanism to operate effectively, it is necessary to classify individuals into various groups based on their degree of risk. Without such classification, those individuals at low risk would be subsidizing those individuals at high risk. Further, those at low risk could very easily decide that the costs of insurance are too high and therefore would not purchase insurance. Because the resulting mix of insureds would have greater average risk than the original mix, it would be necessary to raise premiums. This could result in additional individuals deciding not to purchase insurance because of its excessive cost. This sequence, known as the assessment spiral, could continue and eventually result in the defeat of the insurance mechanism. Hence, risk classification, the domain of the underwriters, is necessary to maintain an equitable and viable insurance system.

\subsection{Principles of U.S. underwriting}

The essence of underwriting is to discriminate among individuals based on their degree of risk. In accordance with this principle, underwriters classify applicants on many factors, including age, sex, health, occupation and lifestyle (e.g., smoker/non-smoker, avocation). Generally, a base premium will be determined for each age/sex grouping which will vary depending on the other underwriting characteristics. Insurers usually maintain several underwriting classes, including preferred, standard, smoker/non-smoker and various substandard classes. The substandard classes typically cover individuals with mortality levels as high as $500-750 \%$ of standard. Individuals with higher levels of mortality cannot be covered because premiums would be too high.

To protect the rights of applicants, underwriters follow certain basic guidelines. Underwriters apply their standards uniformly and must be able to justify their decisions. Information obtained must be relevant to the case at hand and must be maintained confidentially to protect the privacy of the applicants. Unfair discrimination is not permitted. Many of these underwriting guidelines are embodied in the laws and regulations of the states.

\subsection{Government regulation}

The regulatory process in the United States is complex, and leads to the possibility of varying and conflicting laws and regulations because insurance is regulated by the states, not the federal government. While the National Association of Insurance Commissioners (NAIC) makes recommendations that are intended to be uniform in all the states, their proposals are not necessarily adopted by all the states. Conflicting laws and regulations are more likely to arise when new issues are raised. Until a nationwide consensus develops on how best to deal with a particular situation, uniform laws and regulations are unlikely. 


\subsection{Challenges to established underwriting principles}

In recent years, there have been several challenges in the United States to long established underwriting procedures. Perhaps most notable is the charge that various underwriting procedures are unfairly discriminatory. There have been major attempts to prohibit the use of sex as an underwriting factor. Indeed, the State of Montana requires that all newly issued policies be priced on a unisex basis. In general, there has been growing public support for the concept that individuals should not be discriminated against on the basis of factors which would represent a conflict with general public policy. Such items could conceivably include the health of the individual.

\subsection{Mechanics of underwriting}

To effectively underwrite insurance applicants, underwriters may draw on many sources of information, including the insurance application, the agent's report, medical reports, attending physician statements and inspection reports. The applicant can be requested to undergo certain medical tests based on particular criteria such as size of policy, age, or if a response to one of the questions in the application indicates a need for such tests.

The Medical Information Bureau (MIB) is a nationwide clearinghouse for data on insurance applicants. The data is coded and made available to companies to indicate when additional medical underwriting may be desirable. The codes are not used directly as a basis for underwriting decisions.

The degree of underwriting performed generally depends on its cost effectiveness. Underwriting is considered cost effective when costs are less than the additional mortality costs that would be incurred without the underwriting.

\section{Underwriting for AIDS}

\subsection{Why underwrite for AIDS?}

Various studies have found that the expected mortality levels of HIV infected individuals are well above the levels normally considered insurable. Consequently, insuring HIV infected individuals in any of the existing standard or substandard classes would violate considerations of equity and lead to an assessment spiral. Further, the creation of a new underwriting class for HIV infected individuals is not practical unless subsidized by the government because of the high premiums that would be necessary. Therefore, under normal underwriting principles, insurers cannot accept known HIV infected individuals.

The importance of AIDS underwriting is increased because applicants might know more about their risk characteristics than the insurance company. Indeed, some insurers perceive possibly significant antiselection in that individuals who know they have the virus are applying for insurance. The effects of AIDS related antiselection are discussed in the section on the financial impact of AIDS.

\subsection{Public policy concerns}

Currently, the United States does not have a comprehensive policy to allocate the medical care costs of the epidemic. Many AIDS victims who cannot obtain health insurance have no recourse but to deplete their resources and subsequently qualify for Medicaid, the federal-state insurance program for the needy. 
It has been argued that insurers should not be permitted to exclude HIV infected individuals from health insurance coverage because of public policy concerns that such individuals have health insurance. For example, the National Academy of Sciences has argued that until a comprehensive nationwide policy for paying medical claims for HIV infected individuals is developed, health insurers should not be permitted to underwrite for AIDS.

Insurers believe that the provision of medical care for AIDS victims is the responsibility of society. It is unreasonable, both on a temporary and permanent basis, to expect particular segments of society, such as insurers and their policyholders, to fund the necessary care.

Another reason put forth to prohibit underwriting for AIDS is that health insurance is an entitlement. However, insurers maintain that HIV infected individuals are not entitled to insurance any more than are individuals with other serious impairments. Indeed, it would be unfairly discriminatory for insurers to provide coverage to HIV infected individuals, while at the same time denying coverage for those with other impairments. Following this reasoning, the State of Washington requires insurance companies to underwrite for AIDS in the same way they underwrite for other diseases. Insurers believe that these requirements are consistent with insurance laws which require that individuals with dissimilar risks be grouped separately and charged separate rates.

Fifteen states now have high-risk insurance pools specifically for persons who cannot get private health coverage. These pools enable those with life-threatening illnesses, including AIDS, to obtain insurance at rates that are higher than the average for their state but are still affordable. These pools are established by the states and funded from general revenues or other broad-based supporting mechanisms. There is no testing or underwriting involved, but applicants must live in the state and prove they cannot get health coverage in the voluntary market. The Health Insurance Association of America supports federal legislation that encourages high-risk pools. Thirteen additional states are now considering them.

\subsection{AIDS underwriting}

For the most part, those who argue that insurers should cover HIV infected individuals on public health grounds generally limit their case to health insurance. For life insurance, they agree that insurers need not cover HIV infected individuals. While AIDS victims have a clear need for payments for health care, no such need exists for life insurance payments. The arguments used to oppose AIDS underwriting for life insurance relate more to the underwriting methods applied. These issues will be discussed in the context of insurers' policies regarding AIDS underwriting.

To screen applicants for HIV infection, insurers rely primarily on HIV antibody tests and on questions asked in the insurance application. The questions asked generally focus on whether the individual has ever been diagnosed as having AIDS or HIV infection or if the individual has any of the symptoms of the disease. While some applicants might not answer these questions truthfully, insurers feel that false answers are material misrepresentations, which could be challenged. Indeed, many AIDS claims occurring within the first two policy years are challenged on this basis. 


\subsection{AIDS antibody tests}

Because many experts believe that between $65 \%$ and $100 \%$ of all HIV infected individuals will eventually contract AIDS, screening for HIV infection is one of the most effective underwriting tools currently in use. While it is possible that some HIV infected individuals will never contract AIDS and never become sick, it is nonetheless appropriate to exclude them from coverage because seropositivity indicates a high probability of sickness and death. The situation of HIV infected individuals is no different from that of individuals with high blood pressure who never develop heart disease, yet cannot purchase insurance at standard rates.

In most jurisdictions, the testing protocol employed to determine the existence of HIV infection consists of 2 ELISA tests followed by 1 Western Blot test. Experience has demonstrated that these tests accurately detect the presence of HIV infection. Critics have contended that the tests generate a significant number of false positives, which would result in the unfair denial of insurance to otherwise healthy people. However, the CDC recently stated, "The predictive value of both positive and negative test results for HIV antibody are extremely high in laboratories that have good quality control and high performance standards and that use licensed ELISA tests and the licensed Western Blot or other well-standardized tests". The laboratories used by the insurance industry for HIV tests have been found to have such consistently high performance standards and good quality control.

Because insurers have found AIDS antibody tests to be extremely useful and cost efficient, they have started testing a broader spectrum of applicants. When testing was introduced, many companies limited it to instances where there was medical indication that the applicant might be infected and to large amount policies. However, recently companies have generally extended testing to smaller size policies. Now some companies test all applicants, while those that do not, generally test all applicants for medium and large amount policies.

\subsection{T-Cell tests}

Where applicable laws or regulations do not permit the use of HIV antibody tests, Tcell tests, if allowed, are usually substituted. T-cell tests are sometimes used because they detect impairment of the immune system as opposed to the presence of infection. Because seropositive individuals may not develop impaired $\mathrm{T}$-cells for several years, $\mathrm{T}$-cell tests are not as accurate for underwriting purposes as the ELISA and Western Blot tests. Further, T-cell tests may cause the rejection of certain individuals who are not HIV infected.

\subsection{State regulations}

Until recently, legislative and regulatory activity was concerned with the extent to which underwriting for HIV infection should be permitted. More recently, many state legislatures have been considering and passing laws regulating the manner in which such underwriting, particularly HIV antibody testing, is performed. These guidelines have been concerned with confidentiality, informed consent, pre- and post-test counseling and the use of sexual orientation in the underwriting process. In many instances, these laws have been directed at HIV testing in general and not at insurance in particular.

While much attention has been focused on attempts to prohibit AIDS underwriting, there have also been some attempts to encourage consistency in underwriting. In particular, as mentioned earlier, the insurance department of the State of Washington promulgated a 
rule establishing minimum standards to be met by insurers in underwriting the AIDS risk. The rule stated that underwriting considerations for AIDS should be consistent with underwriting considerations for other diseases. While many in the industry feel that the Washington regulation should be adopted as the standard nationwide regulation, most states that have adopted regulations or passed laws on this issue have restricted insurers' ability to underwrite for the AIDS virus

In California, a law was passed that prohibits testing for HIV antibodies for all forms of life and health insurance, while permitting the use of T-cell tests. The City Council of Washington, D.C., passed a more restrictive law which prohibits all tests, including T-cell tests. In 1987, the insurance departments of both New York and Massachusetts issued regulations prohibiting the use of HIV antibody tests for health insurance applicants.

\subsection{Preserving the right to underwrite}

The industry has in many cases responded to testing restrictions by challenging in court the validity of these regulations and laws. In Washington, D.C., the industry lost its challenge. While the court recognized that the ban seemed unreasonable, it felt that there was no legal justification to set it aside. Because of the difficulties involved in selling insurance in such an environment, close to $90 \%$ of Washington, D.C.'s, insurers have withdrawn from that market. In Massachusetts and New York, upon the request of insurers, the courts issued temporary injunctions preventing the test ban regulation from becoming effective pending the outcome of the industry's lawsuits. In New York, the court later ruled that the department's regulation was, in fact, arbitrary and capricious, making the injunction permanent. All testing is currently permitted in New York.

More recently, there have been legislative attempts to expand insurers' authority to test applicants for HIV infection in those jurisdictions where such testing is currently limited. In California, a bill to change current law so as to permit testing includes a proposal for a state risk pool for individuals unable to obtain health insurance. The risk pool would help allay concerns that victims of AIDS will be unable to pay for their health care needs.

Several bills to expand insurers' authority to test are also under consideration in Washington, D.C. Because the proposed D.C. bills would continue to restrict, albeit to a lesser extent, the ability of insurers to test, the industry considers these bills to be unacceptable. To rectify this situation, insurers are trying to demonstrate to the D.C. insurance department the potential future implications of AIDS and HIV on the industry. Insurers hope that the department will understand the need to amend the present law in ways the City Council has been unwilling to consider so far. Reversing existing bans on HIV antibody testing will be a formidable task.

\subsection{Continued challenges}

In the first quarter of 1988, Hawaii and West Virginia introduced legislation that would prohibit life and health insurers from denying coverage to persons diagnosed as having AIDS. Had these bills passed, they would have been the first prohibiting adverse underwriting decisions for people with AIDS. Fortunately, both these proposals were defeated. 
It is evident that the legal and regulatory environment concerning AIDS underwriting continues to hold uncertainties for insurers. While certain states seem to be developing greater recognition of insurers' needs to underwrite for AIDS, others continue to propose legislation and regulations that would limit the effectiveness of AIDS underwriting. To the extent that such laws and regulations continue to be proposed, insurers will have to defend their need to underwrite in accordance with established principles.

\subsection{AIDS underwriting guidelines}

Certain states have introduced, or are considering introducing, guidelines for HIV testing and AIDS underwriting. These guidelines generally prohibit the use of sexual orientation in the underwriting process and require strict confidentiality standards as well as provision of informed consent and pre- or post-test counseling. Insurers are opposed to these guidelines when they force underwriting for AIDS to be different from underwriting for other illnesses and diseases.

Discrimination on the basis of sexual preference is generally considered to be in conflict with social policy in the United States. NAIC issued an AIDS underwriting guideline in 1986 prohibiting attempts at determining an applicant's sexual orientation. While such procedures may be practiced by a few insurers, the industry's stated position is that this kind of discrimination is undesirable and should not be used. Most insurers comply with this position. Nonetheless, certain states have felt it necessary to specifically prohibit the use of sexual orientation in the underwriting process.

It is necessary to safeguard the results of HIV antibody tests with the strictest standards of confidentiality because seropositive individuals are often stigmatized. Indeed, confidentiality concerns have been cited as one of the primary reasons for prohibiting insurers from testing for HIV antibodies. However, even before states started to pass laws requiring confidentiality, insurers were scrupulous in maintaining the highest standards of confidentiality. Indeed, at hearings conducted by the California Assembly Committee on Finance and Insurance in December 1987, the chairman of the committee concluded that there was no compelling evidence that confidentiality problems exist in the states that allow HIV testing by insurers.

The State of Vermont recently passed an AIDS "Bill of Rights". While some of the more severe restrictions in earlier versions of the bill were deleted from the final version, the bill still contains some disturbing provisions. In particular, the final version of the bill requires that if an insurer performs HIV antibody tests, the agent must read aloud to the applicant a statement indicating the reasons the test is being performed and the significance and accuracy of the test. Further, an individual who tests positive must be permitted to be retested upon request three years after the initial test. Some of the more restrictive requirements considered in earlier versions of the bill included a two-year moratorium on testing for health insurance, a requirement that insurers provide each person tested with one session of post-test counseling and punitive damages for violations of confidentiality. Despite the fact that these restrictions were removed, the requirements of the Vermont bill are, nonetheless, in certain regards, still more strict than those required by many other states. 
The State of Maine has passed a law that requires any person or organization that requests someone to take an HIV antibody test to provide that individual with both preand post-test counseling. This law, which will become effective in August, is unique in that it requires personal counseling. Insurers cannot distribute Red Cross brochures, as is the practice in certain other states that require counseling, to satisfy this requirement. Insurers are currently trying to determine the extent of the counseling required, as this matter is not fully described in the law.

\subsection{Public acceptance}

Despite recent challenges, it is encouraging to learn that during the past 18 months all state legislatures that have considered anti-testing laws have rejected them. This heartening news comes at a time when opinion polls are showing that the public is beginning to appreciate the need of insurers to test applicants for HIV infection. Surveys done by the American Council of Life Insurance (ACLI) found that while in 1985 only $49 \%$ of Americans agreed there was a need for insurers to test applicants for HIV infection, $56 \%$ felt this way in 1986 and $61 \%$ in 1987. It is evident that a majority of Americans currently support testing and that the size of this group has been increasing.

While the industry must maintain continued vigilance to preserve its ability to underwrite insurance applicants in accordance with longstanding underwriting principles, it is clear that its persistence in stating its position has helped educate legislators, regulators and the public about the need to underwrite effectively for AIDS.

\section{Financial impact}

\subsection{Overview}

This section will focus on the financial impact of the AIDS epidemic on insurers. The industry has been shouldering, and will continue to shoulder, a large share of the nation's financial burden arising out of the AIDS epidemic. This is a result of the large number of AIDS victims who have insurance and the combined effects of antiselection and underwriting limitations.

In the early 1980s when the AIDS epidemic began to attract attention, many insurers felt it would not have a major financial impact on their business. Most AIDS victims were gay men and intravenous drug abusers (IVDAs), who were not believed to be proportionately represented among the insured population. The relatively small number of AIDS claims experienced in the early 1980 s reinforced this impression. However, as AIDS claims mounted and it became clear that current claims levels were only the "tip of the iceberg", insurers realized they would, in fact, bear a significant share of the mounting costs of the epidemic.

To meet this challenge, many insurers started to track AIDS claims levels. As these levels increased, various organizations began to perform surveys to determine the industrywide impact of the epidemic. The results of these surveys were sobering and showed that the epidemic was having a major impact on the industry. It became apparent that strategies to manage the impact of the epidemic needed to be developed. 


\subsection{Tracking AIDS claims}

While the monitoring of AIDS claims today is more refined than it was in the past, it is widely believed that substantial underreporting exists. The problems encountered include difficulties in modifying the system to collect this type of data, shortcomings in the coding system and hesitancy on the part of medical practitioners to assign AIDS codes. In New York City, a special complexity exists because the local law does not permit the cause of death to be revealed on death certificates made available to insurers.

Extensive data on AIDS claims has been developed only in the last couple of years. Such data tends to cover only recent experience because of the difficulties involved in developing data for prior experience. As the various problems are resolved, more accurate data on the AIDS claims incurred by the industry can be expected. Until then, all figures for reported claims must be assumed to be understatements.

\subsection{Industrywide AIDS claims}

Last year, the ACLI conducted a survey of life and health insurers to determine the total level of AIDS claims paid by the industry in 1986. Based on this survey, which includes group and personal insurance, the ACLI estimates that the industry's 1986 AIDS claims amounted to $\$ 292$ million. This represents six tenths of $1 \%$ of the industry's total 1986 life and health claims from all causes.

The estimate of $\$ 292$ million is most likely an understatement of the level of AIDS claims because no attempt was made to adjust for underreporting. Further adjustments are also necessary because the ACLI survey excluded AIDS claims for certain important categories of group insurance business, such as administrative services contracts, in which the insurers' role is primarily administrative, and contracts that provide only excess risk protection. As such contracts account for the majority of group health business at many companies, this understatement could be substantial.

\subsection{Trends in AIDS experience}

Sharp increases in claims have been found in various surveys of insurers. In a recent survey of group insurers, the North American Reassurance Company found that group medical AIDS claims increased 50\% annually between 1985 and 1987, while group life AIDS claims rose $188 \%$ from 1985 to 1986 and another $73 \%$ from 1986 to 1987 .

In informal surveys of individual life insurers, Tillinghast, Nelson and Warren found similar results. For 1985,438 ordinary life AIDS claims totalling $\$ 24$ million were found, while for 1986, 1,913 AIDS claims totalling $\$ 85$ million were found. Although the number of insurers responding went up by $50 \%$ between 1985 and 1986, the amount of claims went up $250 \%$, signifying substantial increases in AIDS claims. For reinsurance, the Tillinghast surveys found that AIDS related reinsurance claims, as a percent of all reinsurance claims, rose from $0.7 \%$ in 1985 to $2.1 \%$ in 1986 .

While improved tracking of AIDS claims accounts for part of these increases, the major reasons for the increasing levels of AIDS claims are the rising number of AIDS cases in the American population and the widely perceived AIDS related antiselection. 


\subsection{AIDS related antiselection}

Various analyses have been performed to determine the extent of AIDS related antiselection. These studies have found that the average time a life insurance policy has been inforce at the time of death of AIDS victims is significantly shorter than the policy duration at death of other ordinary life policyholders. Further, the average size AIDS claim is substantially higher than that for non-AIDS claims. While the techniques employed in many of these studies often cannot prove conclusively that antiselection exists, the levels of differences between AIDS and non-AIDS claims have been so high as to provide substantial evidence that significant antiselection is occurring.

In a survey of 1985 AIDS claims, the ACLI found that $44 \%$ of all amounts paid for individual life AIDS claims were paid on policies that were within two years of issue. For typical ordinary life claims, $9 \%$ of all claims are paid within five years of issue, suggesting significant AIDS related antiselection. These results need to be interpreted with caution, however. Because AIDS victims generally die at younger ages than the typical policyholder, it is to be expected that the typical AIDS related claim would be at an earlier duration than the typical ordinary life claim. A more meaningful comparison would be against all policyholders who die at relatively young ages to see if AIDS related claims are occurring at earlier durations. While such analyses have not yet been conducted, it is likely that if they were they would indicate that antiselection levels are not as dramatic as the $44 \%$ figure would suggest. Nevertheless, it seems clear that considerable antiselection is occurring.

Comparisons of the average AIDS related death benefit with the average death benefit on all other policies also indicate a high degree of antiselection. The Tillinghast survey found that in 1986 , the average ordinary life AIDS claim was $\$ 44,500$, while the typical claim from all causes was $\$ 8,400$, yielding a ratio greater than 5:1. Again, the results need to be interpreted with caution. The average AIDS victim is relatively young, and bought his/her policy more recently than the typical claimant. It is to be expected that the average AIDS claim will be greater than that of the typical policyholder. A more refined analysis would compare the average death benefit for AIDS with the average death benefit from all causes for policyholders with similar age distributions. Although the ratio of AIDS claims to non-AIDS claims would be substantially lower than $5: 1$, it is likely that this analysis would also indicate large-scale antiselection.

The Transamerica Life Companies have compared their average AIDS claim by year of issue with their average non-AIDS claim. For business issued before 1980, when the AIDS risk was unknown, the average AIDS claim is less than $50 \%$ of the average overall claim. For business issued between 1980 and 1983, when the groups at highest risk were aware of the disease, the average AIDS death claim soared to five times the overall average size claim. Their analysis covered only Transamerica business and did not consider variations in age/sex and other underwriting characteristics between AIDS victims and typical policyholders. Nevertheless, their work again suggests that much antiselection has been occurring.

While individuals who know they are infected might apply for a job in the hope of obtaining insurance, it is widely believed that group insurance is generally less subject to the effects of antiselection than is personal insurance because employers typically employ a 
cross section of persons who can be expected to be in reasonably good health. This does not necessarily hold for small group plans where, for example, coverage may be specifically sought for a relative in poor health. Likewise, for certain individually underwritten group coverages, individuals who know or believe they are at risk might antiselect against the company.

There is, however, one area of group insurance in which it is widely believed substantial AIDS related antiselection is occurring. This is in the area of group conversions. Group policies generally provide an option that permits terminating employees to continue their insurance coverages on an individual basis without evidence of insurability. Exercise of the conversion option has always been associated with high levels of antiselection, and experience with AIDS has been no exception. This poor experience on group conversions in general and AIDS related conversions in particular has been exacerbated by COBRA, a federal law that mandates that employees may retain their health coverage for 18 months after termination of employment. (The acronym COBRA stands for Consolidated Omnibus Budget Reconciliation Act.)

\subsection{More recent trends}

The discussion thus far paints a rather gloomy picture and indicates that in all likelihood the situation will deteriorate before it becomes better. However, some trends are developing which seem to show that certain aspects are starting to improve. In particular, at some companies, the average size AIDS claims has fallen. Transamerica Life Companies reported that for business issued in 1984 and later, the average AIDS claim is three times the average claim for all other causes as compared to a ratio of five times for business issued between 1980 and 1983. This decline might be attributable to effective AIDS underwriting implemented for larger size policies. While the ratio of three times for recent issues is still higher than desirable, the decline in the ratio is nonetheless an encouraging sign and indicates that actions can be taken to make the epidemic more manageable.

For health coverages, in addition to underwriting, case management, which aims to provide quality care in the most cost effective way, has greatly reduced insurers' costs. Blue Shield of California has reported that it saved an average of $\$ 8,000$ per AIDS patient over an 18 month period through case management, while Equicor estimates it can reduce by $40 \%$ the costs of AIDS treatment with case management.

Despite these improvements, there are still obstacles that need to be overcome. In particular, for case management programs to be successful, patients must be referred as early in their illness as possible. Many AIDS victims are not referred for case management until they have already been hospitalized. Further, accurate cost data must be developed to measure the potential and actual savings of these programs. Despite these problems, case management remains one of the most effective ways to reduce the health care costs of AIDS victims.

While case management and enhanced underwriting have helped control the costs of the epidemic, other factors are causing the costs to rise. One such factor is the widely used drug AZT, which costs close to $\$ 10,000$ per year. As increasing numbers of asymptomatic HIV infected individuals start using AZT, the costs associated with this drug will rise. Other 
drugs under consideration, but not currently approved for use in the United States, include AL721 and Ribovarin. As AIDS victims respond to these treatments and live longer, and as new drugs and treatments are introduced, the lifetime medical costs of AIDS victims might rise. Further, as the AIDS caseload continues to increase, the overall level of AIDS related costs will also rise.

\subsection{Variations by company}

While AIDS is clearly a major problem for the insurance industry, not all insurance companies have been affected in the same way. Variations are caused by many factors, most notably the different structures and operating procedures of the various companies. Different target markets and variations in the application of underwriting standards cause differences in the impact of AIDS for individual coverages. Those insurers that marketed aggressively in the late 1970s and early 1980s, particularly in areas or among age groups where HIV infection may be more prevalent, have been especially hard hit.

While the level and scope of underwriting play a role in determining the extent to which a company's group business has been impacted, it is generally agreed that a prime concern is the nature of the groups that the company insures. Insurers that market to those groups which tend to have a higher proportion of HIV infected individuals have been hit more severely than others. One interesting result reported by the North American Reassurance Company Survey is that the proportion of AIDS claims is greatest for groups with more than 1,000 or fewer than 25 employees. Small employers might have poor results because of antiselection while intermediate size employers might be particularly careful in their hiring procedures, causing them to have better results than large employers.

As a demonstration of the variations that exist among companies, the North American Reassurance Company Survey found that while $1.17 \%$ of total group life claims were due to AIDS, some companies reported figures as high as 4 to $7 \%$. The ACLI survey of 1986 AIDS claims also found significant variations among companies. In particular, the AIDS claims of a substantial number of companies (those that in aggregate paid over $40 \%$ of the industry's ordinary life claims) were less than one half of $1 \%$ of their total ordinary life claims. At the opposite extreme, a substantial number of companies (those that in aggregate paid more than $35 \%$ of the industry's ordinary life claims) reported that AIDS claims exceeded $1 \%$ of total claims. These differences indicate that each company must carefully monitor its own experience. Industrywide levels of claims are not a good predictor for the level of claims expected to be incurred by any particular company.

\subsection{The purchasers of insurance}

Increased claims costs must necessarily be reflected in the price that policyholders pay to obtain coverage. Individuals seeking to buy insurance will find, in many instances, that the cost of insurance is rising as a result of the epidemic. In July 1987, the New York State Insurance Department approved a $12.1 \%$ rate increase for New York City clients of Empire Blue Cross/Blue Shield, a health insurance program. A spokesman for Blue Cross indicated that the progression of the AIDS epidemic was one of the reasons for the rate 
increase. Indeed, the rate increase for New York City was $2.2 \%$ larger than that for the Albany, New York, area, reflecting the greater concentration of HIV infected individuals in New York City. It is apparent that the AIDS epidemic will affect costs for all policyholders.

An extreme example of the potential impact of AIDS on purchasers of insurance is the experience of Washington, D.C. As mentioned earlier, in 1986, the district's City Council passed a law that prohibited insurers from effectively underwriting for AIDS. As a result, close to $90 \%$ of the companies that formerly sold individual insurance in Washington suspended all sales in the district. Instead of maintaining coverage for HIV infected individuals, the district's law made it more difficult for all, regardless of HIV status, to obtain coverage.

To date, the expected increase in AIDS related claims has had only a modest impact on group insurance rates and reserves. However, as the impact on group insurance becomes greater, employers who provide life and health insurance for their employees will be increasingly affected by the epidemic. Premium increases resulting from AIDS will serve to quicken the rapid pace at which rates have been rising as a result of health care cost inflation.

\subsection{The future}

The various surveys of AIDS related claims reveal that these claims form an increasing portion of all life and health claims in the United States. As the number of AIDS cases continues to rise, it is reasonable to expect that the level of AIDS claims will rise commensurately. To more precisely measure the expected future AIDS claims levels, the Society of Actuaries performed a study in 1987 which found that, while future AIDS claims on life insurance might exceed $10 \%$ of all life claims, there should not be a flood of insolvencies. In other words, AIDS will present major challenges to the life insurance industry, but the epidemic is likely to be manageable if dealt with appropriately.

The Society of Actuaries' report, entitled "AIDS, HIV Mortality and Life Insurance," projects that there could be $\$ 70$ billion in AIDS related life insurance claims before the year 2000. The sources of these claims are

(1) Individual life insurance inforce as of $12 / 31 / 86-\$ 30$ billion,

(2) Individual life insurance issued after $12 / 31 / 86$ - $\$ 20$ billion and

(3) Group life insurance inforce as of $12 / 31 / 86-\$ 20$ billion.

Since no projections were developed for new issues of group life insurance, total AIDS related life insurance claims projected would exceed $\$ 70$ billion. Strategies to contain and fund these costs need to be developed. For new issues, improved underwriting can be expected to help control antiselection.

The Society's report does not project the expected financial impact on health insurers. The Health Insurance Association of America has projected that health insurers will incur $\$ 16$ billion in AIDS related claims through 1991. By 2000, some have estimated that total health claims could reach $\$ 50$ billion.

These projections show that expected AIDS claims could be substantial. The Society of Actuaries report points out that the dividend and other margins of most companies will be able to absorb the losses caused by the epidemic. Thus, even under the worst of scena- 
rios, most insurers should be able to survive the AIDS crisis. A recent report by Moody's Investors Service sounded a similar theme, noting that the mortality and morbidity costs of the AIDS epidemic are "unlikely to cause widespread insolvencies in the private U.S. insurance industry".

While these thoughts are reassuring to policyholders concerned about potential insolvencies, insurance company managements will need to monitor the situation closely to maintain control and to keep the impact on insurance costs to a minimum. Funding mechanisms to pay for the large costs need to be established. Pricing methodology, in a generation which thought that changes in mortality could only be for the better, needs to be reevaluated. Strict underwriting guidelines must be observed. With careful planning and appropriate allocation of resources, most insurance companies can expect to weather the storm.

\subsection{Funding A1DS claims}

To develop the funds necessary to pay for the costs of the epidemic, insurers have developed a variety of approaches. For individual coverages, effective strategies would include the reduction of dividends for participating policies and increased charges for policies that do not guarantee premiums and/or mortality charges. The funds so developed could be used to set up a special reserve that would provide for AIDS claims.

Significant problems need to be resolved in order to be able to effectively implement these strategies. A key question is to whom to assess the extra costs brought about by AIDS. One viewpoint would be to spread the cost to as broad a base of policyholders as possible. Another approach would be to increase costs in proportion to the expected impact by classification (e.g. age/sex). Additional complexity is caused by competitive considerations.

While the experience rating mechanism provides substantial protection for group insurers, it is not a panacea. Because customers can switch carriers and frequently do, particularly when there is a large rate increase, insurers cannot recover all losses. Further, there is often a time lag before emerging experience can be reflected in rate increases. The increasing use of excess risk contracts also places additional risk on the insurer. Some group insurers have responded to these challenges by increasing risk charges to some extent. An important strategy in the group area will be to work with customers on plan designs which will appropriately respond to the added risk of AIDS.

Reinsurance can also play a role in limiting insurers' AIDS related costs. A recently developed strategy is to use catastrophe reinsurance for AIDS claims. Considerable interest has been expressed in this product for individual life insurance because of the limited opportunity to raise rates on individual coverages. One reinsurance strategy that some group insurers have implemented is to change reinsurance retention limits, thereby transferring a larger portion of their risk to reinsurers.

\subsection{Limiting exposure to A1DS}

To limit AIDS related claims, it has been suggested that insurers issue policies which exclude these claims. Objections have been raised to this strategy because it can be difficult to determine whether claims are AIDS related. A strong potential exists for insureds to disguise the nature of their claims in the case of AIDS. 
An additional strategy is to increase the length of the contestable period for AIDS claims. The length of the contestable period is currently prescribed by laws and regulations. Therefore, it would first be necessary to convince legislators and regulators that such changes are needed and appropriate.

\section{Conclusion}

The AIDS epidemic has caused the United States to focus more sharply on its system for meeting health care costs including the appropriate role of life and health insurers. The extent to which insurers might be expected to bear a share of the increasing costs that are emerging on HIV infected persons not currently insured is a major issue being examined. Underwriting principles which would exclude HIV infected individuals from coverage are coming under closer scrutiny.

The facts presented in this paper indicate that the obligations of insurers for AIDS should be the same as those for all other diseases and illnesses. AIDS, though tragic and devastating, needs to be viewed in the context of heart disease, cancer and other life threatening diseases.

Because of antiselection and various restrictions on AIDS underwriting, it might be suggested that insurers and their policyholders have been financing a greater share of AIDS costs than considerations of equity would deem appropriate. To preserve equity and to maintain the financial viability of the insurance mechanism, insurers cannot be expected to contribute more than their responsibilities deem appropriate. Insurers must be permitted to treat AIDS an any other disease.

\section{Addendum}

While this paper focuses on the insurance industry's financial responsibilities in the AIDS crisis, the industry also has responded in human terms.

Individual insurance companies, along with the life and health insurance industry's major trade associations, have been in the forefront of educating the public about AIDS, funding AIDS research, and providing help to victims.

Here are highlights of these efforts:

- The American Council of Life Insurance (ACLI) and the Health Insurance Association of America (HIAA) gave $\$ 900,000$ to the American Red Cross to support public education efforts aimed at preventing the spread of AIDS. The two trade groups also made grants of $\$ 75,000$ each to the National Black Nurses Association and the National Coalition of Hispanic Health and Human Services Organizations to develop AIDS education programs for the black and hispanic communities. The ACLI and HIAA also gave $\$ 47,000$ to the Whitman-Walker Clinic, Washington, D.C., for the purchase of medical and dental equipment. The clinic is used chiefly by Washington's gay community.

- The Life and Health Insurance Medical Research Fund has given one of its six grants to a medical researcher working on AIDS, and one of its three scholarships to a student studying AIDS. 
- The Allstate Insurance Companies sponsored a major conference on strategies to cope with AIDS in the work place. One of the aims was to develop understanding for the AIDS victim on the part of co-workers.

- The Connecticut Mutual Life Insurance Company underwrote performances of "As Is", a highly acclaimed drama about AIDS sufferers. The proceeds from the performances went to AIDS Project/Hartford (Hartford, Connecticut), an AIDS prevention and patient care volunteer group.

- The John Hancock Mutual Life Insurance Company cosponsored a 10-kilometer walkathon for the Boston AIDS Action Committee, the largest AIDS service and education organization in New England. The walkathon raised almost $\$ 750,000$. Part of the money was earmarked for the World Health Organization's AIDS activities.

- The Lincoln National Life Insurance Company awarded $\$ 150,000$ to the non-profit Hudson Institute, Indianapolis, Indiana, to fund an AIDS study.

- The Metropolitan Life Insurance Company sponsored, without commercial interruption, a \$4 million national television special "The National AIDS Awareness Test: What Do You Know About Acquired Immune Deficiency Syndrome?" Surveys found the program greatly increased viewer knowledge of key risk behaviors.

- Mutual of New York (MONY) has made major grants to AIDS education and patient care projects. These include a hospice for AIDS patients, a street-theater educational program, and a bereavement and sensitivity training program for caregivers.

- The New York Life Insurance Company underwrote a major fund-raising dinner for the American Foundation for AIDS Research, raising more than a quarter of a million dollars for the foundation.

- The Standard Insurance Company spearheaded efforts to raise money for the Cascade AIDS Project in Portland, Oregon. The money was used to hire an AIDS educator and make an educational videotape.

- A pioneer in AIDS related activities, the Transamerica Life Insurance Company has contributed hundreds of thousands of dollars to AIDS research and service groups.

An underlying theme of this paper is that AIDS is a societal problem and that the insurance industry cannot be expected to shoulder more than its fair share of the financial burden of the AIDS epidemic. However, as this brief addendum points out, the industry has responded vigorously to the crisis. But the fight against AIDS must be on all fronts - education, prevention, research, and help to victims. 